third stage of anæsthesia. After a quarter of an hour the trachea was reached and opened, but directly air entered and the obstruction was entirely relieved breathing became shallow and almost ceased, the pulse, which had been full and strong before, became small and slow, and pallor of the face appeared, which only gave place to returning colour and respiration after three or four strong compressions of the chest walls. This remarkable sequence of circulatory phenomena was due, in my opinion, to the sudden loss of stimulation to the respiratory mechanism which had been working vigorously under the inflyence of partly venous blood and thereby strongly emptying the right heart by ample thoracic movement.

CASE 4. Epithelioma of the larynx.-The patient was a man, aged sixty years, thin, wiry, and alcoholic, his voice was almost gone, and he had laryngeal stridor and dyspnoea on exertion. There was deep, diaphragmatic respiration ander chloroform; his colour was somewhat dusky, but his pulse was strong and regular at 96 . Tracheotomy was performed. No pallor or respiratory cessation occurred here, but the breathing becoming quiet and shallow on insertion of the tabe the pulse fell in force and frequency at the same time.

CASE 5. Tuberculous disease of the right thyroid cartilage.The patient was a boy, aged eighteen years. He was very thin and anæmic, with a hard swelling over the right side of the larynx. He was suffering from severe dyspnoea painful to witness. When requested to fill his chest the upper part expanded, but breathing usually was mainly diaphragmatic. He had hoarseness for two years previously and increasing respiratory obstruction for two months, culminating in attacks of acute asphyxia during the three previous nights. Sleep was now impossible, bat the patient could lie down flat. His pulse was 84, small and weak, though regular. Chloroform was taken on Skinner's mask with regular hoarse inspirations which passed into a deep rhythm, though air entry was severely obstructed. Operation was begun. The palse was good. When, however, the head was extended backwards the brawny swelling in the throat almost entirely occluded the passage of air. The face and ears were deeply cyanosed, secondary pallor commencing. The pulse was atill regular. The head was flexed, the moath was opened, and the tongue was drawn forward; the tissues over the swelling were divided and breathing was much freer. Forty minutes from beginning high tracheotomy was performed. After insertion of the tube some obstruction arose from ropy mucous, but allowing the patient to come round a little this, with a little blood, was coughed up, and at the end of one and a half hour's operation he finished well, was warm, of good colour, and with a pulse at 84 .

To illustrate the very grave and alarming symptoms which arise under chloroform from sudden obstruction to breathing in a previously unobstructed patient the following case may prove of value.

CASE 6. Accidental division of the right recurrent laryngeal nerve.-The patient was a male, aged thirty-five years, thickset and well nourished, suffering from hygroma of the thyroid gland on the right side. Breathing was normal. A.C.E. mixture was administersd on Rendle's mask throughput; there was typical anæsthesia during the first half-hour of operation, when the right recurrent laryngeal nerve was accidentally cut by the operator; inspiratory stridor set in and gradually became more marked. There was, however, no real dyspncea till after operation, when the obstruction from paralysis of the right vocal cord became very severe and despite head extension and drawing forward of the tongue extreme cyanosis and irregularity of the pulse supervened with very deep inspiratory efforts. Secondary pallor accompanied this acute asphyxia and the surgeon was compelled to intubate the larynx with an O'Dwyer's tube to relieve the symptoms. When the breathing became quieter the patient was removed to bed and after complete recovery from the anæsthetic the tube was coughed out and he subsequently did well.

In certain of the foregoing cases, though tracheotomy was performed, it was not undertaken for the purpose of alleviating asphyzia during anæsthesia, but had been designed beforehand as part of the remedial treatment for the disease ; in this last case, however, the very grave symptom of cardiac irregularity supervened rapidly upon espiratory obstruction, and it was this secondary circulatory failure which rendered laryngeal intubation or tracheotomy necessary to save the patient's life.

W elbeck-street, $\mathbf{W}$

\section{CLINICAL REMARKS ON SOME ADVANCED FORMS OF URETHRAL STRICTURE TREATED BY A COMBINED URETHROTOMY AND PERINEAL SECTION.}

BY REGINALD HARRISON, F.R.C.S. ENG., SURGEON TO ST. PETER'S HOSPITAI.

IN some clinical remarks I recently offered ${ }^{1}$ on the commoner forms of urethral stricture I reserved for separate consideration certain instances where the methods of treatment then referred to were unlikely to prove of much benefit for the reasons that either the obstractions were too "burnscar"-like and contractile to dilate or too tough or extensive to divide from within the urethra. In addition to such characteristics these strictures are not unfrequently complicated with fistulæ or tortrous routes in the perineum and scrotum through which both urine and pas escape. Hence the discomfort of the patient is often greatly added to. Cases answering to this description are generally re garded as being best treated by some form of perineal section or, as it is sometimes called, external urethrotomy and it is to this point I desire now to confine myself. As a contribation to this subject I published a series of cases ${ }^{2}$ where the usual operation of perineal section as undertaken for stricture in the deep urethra had been greatly simplified and its safety and efficiency increased by combining with it internal urethrotomy. Strictures of the class now under notice are but rarely impassable to some form of instrument and as by reason of the urinary fistulæ which so often complicate them they are seldom urgent in their nature time is allowed not only for effecting an entrance into the bladder by the natural way, but also for ascertaining what may be the outcome of some kind of dilatation. Assuming that the former is accomplished, though dilatation proves futile, the combined operation probably offers the best solution of the difficulty. In describing it, together with such modifications as I have adopted since the publication of my first paper on this subject, I will take in illustration two typical instances in which it was employed.

CASE 1.-A man, aged fifty-one years, whom I saw and operated upon in 1890 had been the subject of a stricture with a strong tendency to contract for some years and had undergone no less than six operations for it, including a divulsion by Holt's method and five internal urethrotomies at various intervals and places. For some months before I saw him the stricture had been contracting and closing in spite of the patient's well-directed efforts with suitable bougies to keep it open. Straining to urinate was constant and prevented continuous sleep, and there was some cystitis with probably pyelitis. It was clear that a free relief must be afforded as structural kidney complications appeared imminent. I performed an internal nrethrotomy with Teevan's modification of Maisonneuve's instrument, as I thought that the latter might not stand the strain put upon it by the cartilaginous character of the tissues which had to be divided. This being done I passed a fall-sized grooved staff (No. 12 English) into the bladder. As the latter was evidently gripped in the deep urethra I had the patient placed in the lithotomy position and I divided in the median line from without inwards such contracted tissues as remained. I thus opened the urethra and found by passing my finger first into the bladder and then hooking it forwards along the urethra in the direction of the penile orifice that the walls of the canal had now been rendered free and unresisting. A fall-sized gum-elastic drainage-tube (such as I have elsewhere described and figured ${ }^{3}$ in connexion with the larger subject of bladder drainage) was passed into the bladder through the wound and retained. The parts were well washed out with a solution of perchloride of mercury ( 1 in 6000 ). The drainage-tube was finally withdrawn on the sixth day and the wound soon closed. Eight years have now elapsed since this operation was practised.

1 The LANCET, April 23rd, 1898.

2 Brit Med. Jour July 18 th, 1885

3 Surgical Disorders of the Ürinary Organs, 4th edition. 
The patient remains in good health and suffers no further inconvenience from his urinary organs than having occasionally to pass a full-sized bougie for himself. I frequently meet him.

CASE 2.-This patient, aged forty-five years, had a tough contractile stricture which had resisted dilatation and was complicated with several urinary fistula of two years' standing. I operated upon him in 1892. He was treated in the same way as the preceding patient and in addition the various fistulæ were opened up and scraped. The result was equally satisfactory and is so far permanent.

Perineal section carried out on these lines has been found to present many advantages. In the first place it is easier to effect a division of the hard and condensed tissues of the perineum, such as generally surround strictures of this kind, upon a fairly large staff than apon a small one or even upon the shouldered staff which Syme used for marking the commencement of the contracted portion of the canal. The freedom or otherwise with which the large-sized instruments move in the canal is sufficient to determine the necessity for proceeding at once with the external section, as well as the precise locality and degree of the contraction which remains. It may seem at first sight in combining these two operations that the magnitude of an ordinary perineal section is in creased. This, however, is not the case, as the division of more or less of the obstruction from within the canal has not infrequently proved sufficient to completely clear the urethra, whilst it invariably tends to limit considerably the extent of any external section which may still be required. Further, it mast be remembered that there is no kind of wound involving the deep aretbra which heals so kindly or is so free from those constitutional symptoms which occasionally follow operations on this canal than tbat where a temporary drain is established for the urine. Again, this point is importantly supported by the results following ruptare of the deep urethra from external violence. Cases of this kind where a perineal section is performed and a temporary drain established compare most favourably, both immediately and remotely, with those where the treatment consists in the retention of a catheter, when this can be passed, the points of distinction being in the former class of cases the absence of septic symptoms of a serious nature and the more favourable character of the scar which results. There is no worse kind of stricture to manage than that following an extensive rupture of the deep' urethra and its treatment by what may be described as the closed method. It is on grounds such as these that I believe the combined operation proves of much benefit in the treatment of some of the most serious and complicated forms of urethral stricture.

Before concluding these remarks I will briefly refer to a class of strictures which I have only incidentally noticed. This is the structurally impassable stricture-impassable alike to instruments and urine and associated invariably with an extraneous route for the urine, probably through the perineum. The latter condition is the result either of nature's effort to provide escape for the urine by abscess and fistula or of the surgeon's, more promptly and directly, by incision. In endeavouring to restore a urethra of this kind and to close a well-worn fistula the surgeon will fully recognise the mechanical and physiological difficalties before him not only in reproducing a portion of the canal which to all intents and purposes is obliterated, but in subsequently fitting it to take up the fanctions connected with the process of natural, or even aided, micturition. It requires no great amount of surgical ingenuity to establish the continuity of the urethra so far as instrumentation is concerned, but to secure a reasonable degree of control or influence over the restored portion of the canal is by no means certain. On the other hand, experience and trial have not infrequently shown that a good urinary fistula has proved an excellent substitute for a bad urethra.

Lower Berkeley-street, $W$.

Torguay Natural History Society. - The report presented at the annual meein $x$ of this society showed that there were 198 members and associates. A special vote of thanks was awarded to Mr. C. H. Wade, M.A. Oxon., M.R.C.S Eng., L.R C.P. L ind, for the large amount of time and trouble he bat devoted to the society.

\section{A CASE OF RECURRENT CANCER OF THE BREAST TREATED BY OÖPHOREC- TOMY AND THYROID EXTRACT.}

\author{
BX G. ERNEST H RRAN. M.B., F.R C.P. LOND.y \\ T.R.C.S. ENG.,
}

SENIOR OBSTETRIC PHYSICIAN TO 'IHE LONDON HOSPITAL, ETC.

A PATIENT, aged forty years, consulted me as to a lump in the left breast. The patient's weight was then $10 \mathrm{st} .3 \mathrm{lb}$. She had had two children, the last thirteen years ago. Menstruation was regular. The characters of the lump led to the opinion that it was cancer, and the patient was advised to see a surgeon. The result of this advice was that in October, 1890, Mr. Treves removed the left breast. Tho whole mamma was removed, but as no glands were dis. covered in the axilla the axillary space was not evacuated. The breast after removal was cut into, and the tumour was found to present all the characters of cancer so well marked that it was not thought necessary to complete the diagnosis by microscopical examination. The patient recovered well from the operation. In July, 1893, her weight was 11 st. 2 lb. In November, 1895, it was 11 st. $1 \mathrm{lb}$. In the beginning of 1896 she began to lose flesh. In May, 1896, she weighed 9 st. $12 \mathrm{lb}$., and in July $8 \mathrm{st} .13 \mathrm{lb}$. After this she gained a little, reaching $9 \mathrm{st} .6 \mathrm{lb}$. in October. Towards the end of December she noticed a lump in the armpit, which induced her to again come for examination. As a result of this on Jan. 4th, 1897, Mr. Treves cut down first upon a lump just above the clavicle and then upon the lump in the armpit. The lump above the clavicle was found to be an indurated fixed gland in such close relation to the subclavian vein that its removal was unadvisable. When the axilla was exposed, a mass of new growth was found quite surrounding the axillary vessels. There were also nodules in the pectoralis major. The new growth was so extensive that the com. plete removal of the axillary growth conld have been effected only by amputation of the upper extremity, and if this had been done the supra-clavicular nodule would have remained. The incisions were therefore closed without any attempt to remove the recurrent growths. The wounds healed well.

As there was no prospect of cure by any other treatment the case in which Dr. Beatson observed disappearance of recurrent cancer of the breast after oöphorectomy and the administration of thyroid extract was put before the patient and her husband, and after consideration they decided to accept this chance of cure. Menstruation had been irregular for about three years, but had not ceased. She had last menstruated on Jan. 3rd, 1897. On March 2nd, 1897, I removed both ovaries. They presented small cysts but were otherwise healthy. As soon as the vomiting caused by the anæsthetic had passed off the patient began to take thyroid extract; at first the glycerine extract made by Allen and Hanburys, then either tabella from Allen and Hanburys or tabloids from Burroughs, Wellcome and Co. She has taken this ever since in as fall doses as she could, varying from $10 \mathrm{gr}$. to $15 \mathrm{gr}$. daily. She has occasionally had to diminish the dose on account of dyspeptic symptoms-vomiting and epigastric pain-thought to be produced by it. On Sept. 27th, 1897, she came up for examination. Mr. Treves and I examined the parts. The supra-clavicular nodule was no longer to be felt. The axillary artery could be felt pulsating, apparently quite free from growth around it. The patient's weight, which on March 27th, 1897, was 8 st. $4 \frac{1}{2} \mathrm{lb}$, is now (May, 1898) 8 st. $10 \frac{1}{2} \mathrm{lb}$. On May $5 \mathrm{th}, 1898$, the patient was eeen by Dr. G. C. Tayler of Trowbridge, who reported as follows: "I examined the operation scars this day and find that they are pale-almost the colour of the neighbouring skinsoft, no adhesion to the subjacent parts, and no deposits of any kind in the surrounding tiesues."

In this case, as in one published by Dr. Beatson, recurrent cancerous growths atrophied after removal of the ovaries and the administration of thyroid extract. The length of time since the operation during which the patient has remained well-fourteen months-is enough to justify the assertion that the course of the disease has teer modified by the treatment. 